\title{
Contra las elecciones. Cómo salvar la democracia
}

\section{Against elections. The case for democracy}

\section{Germán Pérez-Verduzco $\mathbb{D}$}

Universidad de Colima

german_perez@ucol.mx

Libro: Van Reybrouck, David (2017). Contra las elecciones. Cómo salvar la democracia. Madrid: Taurus. Reseña: Recibida el 2 de febrero de 2019 y aprobada el 21 de febrero de 2019.

\section{Cómo citar esta reseña}

Pérez-Verduzco, G. (2019). [Revisión del libro Contra las elecciones. Cómo salvar la democracia, de D. Van Reybrouck]. Reflexión Política 21, 41, pp. 226-228. DOI: https://doi.org/10.29375/01240781.3505

\section{Contra las elecciones. Cómo salvar la democracia}

Antes que nada, y en afán de una mayor honestidad intelectual con el lector de esta reseña, debo decir que el interés en esta obra se ha debido en gran parte a un título que, además de contraintuitivo, resulta un tanto provocador. Empero, dejando de lado sensaciones iniciales y prejuicios, Contra las elecciones. Cómo salvar la democracia es un libro bastante ameno e inteligente en el que su autor, el historiador cultural belga David Van Reybrouck, plantea el problema de las crisis de eficacia y legitimidad en las actuales democracias, y propone la implementación del sorteo como el instrumento político que podría resolver dicha cuestión. Estructuralmente hablando, la obra está dividida en cuatro capítulos, tres de ellos enfocados a discutir las limitaciones de una visión de democracia circunscrita únicamente a la esfera o ámbito electoral, y otro más en donde desarrolla una propuesta capaz de brindar una mayor legitimidad al Estado, sin renunciar por ello a la búsqueda de eficacia al gobernar.

En el primer capítulo, titulado Síntomas, se plantea que las democracias occidentales atraviesan una crisis evidenciada por los datos de diversas encuestas de opinión pública que alrededor del mundo indican que, si bien los ciudadanos tienen una inclinación favorable hacia este sistema de gobierno, en realidad son pocos los que confian plenamente en su práctica. Para Van Reybrouck (2017), tal desconfianza política, aunada al mayor interés de la ciudadanía por participar, genera una brecha cada vez mayor entre lo que el ciudadano piensa que el político debería hacer, y lo que este desatiende. Así, mientras los ciudadanos se frustran por el desajuste que hay entre sus expectativas y la realidad, los políticos, por su parte, piensan que la ciudadanía se rige por valores menos elevados a los suyos, y, por tanto, no toman en serio sus solicitudes.

Además de resaltar esta paradoja, en el planteamiento del problema de Van Reybrouck hay una idea fundamental: la constante aspiración de los sistemas políticos de alcanzar el equilibrio entre eficacia y legitimidad. Aquí coincidimos plenamente con el autor cuando señala que la democracia es la forma de gobierno menos mala al respecto, sobre todo en comparación a la ilegitimidad inherente en una dictadura, o frente al caso hipotético de un país en el que todo tuviera que ser debatido por la ciudadanía y la incapacidad de resolución que eso implicaría (Van Reybrouck, 2017). 
Con todo, las democracias occidentales sufren graves dificultades para brindar soluciones válidas a los problemas actuales (falta de eficacia), y padecen además una escasa aceptación de la autoridad estatal que intenta solucionar tales cuestiones (carencia de legitimidad). En concreto, como síntomas de la crisis de eficacia existen: I) negociaciones más largas para la formación de gobierno; II) un mayor desgaste de los partidos en el poder (evidenciado en el aumento del voto de castigo); y, III) en general, una mayor dificultad para gobernar de manera enérgica y resuelta. Por otra parte, los síntomas de la crisis de legitimidad se aprecian en: IV) un abstencionismo cada vez mayor en elecciones; V) una mayor fluctuación electoral, que implica votantes menos leales a un partido; y, VI) cada vez menos afiliados a los partidos políticos. Estos seis síntomas caracterizan lo que Van Reybrouck (2017) denomina como "síndrome de fatiga democrática".

Una vez planteada la cuestión, en el siguiente capítulo, Diagnósticos, el autor desarrolla algunas de las hipótesis más comunes respecto a quiénes son los culpables de la crisis de la democracia. Primero, analiza los argumentos brindados por los populistas contra los políticos en el sentido de que estos últimos representan una casta ajena a las necesidades del pueblo, $\mathrm{y}$, por tanto, la solución reside simplemente en buscar una mejor representación popular. Luego, revisa las razones esgrimidas por los tecnócratas al culpar a la propia democracia por su crisis y señala que los intereses públicos deberian ser siempre defendidos por expertos, es decir, por aquellos con más conocimientos técnicos para gobernar. Por último, menciona los argumentos de los defensores de la democracia directa, quienes señalan que la solución al problema está en reducir los mecanismos de representación y aumentar aquellos en los que la ciudadanía pueda tener mayor participación, de tal manera que se alcance una democracia más horizontal y transparente (Van Reybrouck, 2017).

Aunque los tres diagnósticos anteriores llevan algo de razón, para el autor del libro todos son inexactos, ya que considera inadecuado reducir la crisis de democracia a una crisis de las personas que se dedican a la política (como hacen los populistas), limitar el ejercicio del gobierno a un asunto de eficacia sin considerar la legitimidad (como hacen los tecnócratas), o rechazar cualquier forma de representación y desconfiar de los actores e instituciones del sistema en general (como hacen los defensores de la democracia directa). Para Reybrouck (2017), en vez de señalar a la democracia representativa como principal culpable, habría que apuntar más bien hacia las limitaciones de la representación electoral y pensar que el modelo es obsoleto al tratar de abordar los retos del siglo XXI, donde además de un combate extremadamente mediatizado y una comercialización en la que el ciudadano es más bien visto como cliente o consumidor, las elecciones solo provocan que "el largo plazo y el interés general cedan ante el corto plazo y los intereses de partido" (p. 67).

Las causas de esta enfermedad del sistema político democrático son descritas por el autor en el capítulo Patogénesis; allí realiza un interesante recorrido histórico desde la antigua Grecia, pasando por algunas sociedades del Renacimiento, las revoluciones francesa y norteamericana en el siglo XVIII, y llegando hasta la democratización de las elecciones en los siglos XIX y XX. A través de este tercer capítulo, Van Reybrouck (2017) resalta la relevancia del sorteo y la rotación en el sistema democrático ateniense en una época en que la elección era considerada un método oligárquico, y donde casi todas las funciones de gobierno se asignaban aleatoriamente, sometiendo el principio de igualdad al de seguridad solo cuando la situación lo ameritaba, es decir para los cargos financieros o militares más elevados (Reybrouck, 2017). Asimismo, el autor brinda un dato poco citado en la literatura sobre el tema: la frecuente coincidencia entre la utilización del sorteo como instrumento político y periodos de progreso cultural y prosperidad en los Estados urbanos, tal como aconteció en la Venecia y Florencia renacentistas.

En este capítulo también se aborda el hecho de que, con la llegada de la República, los líderes revolucionarios estadounidenses y franceses sustituyeron la legitimidad divina por una legitimidad electoral que consistía en que los mejores fueran elegidos para gobernar. No obstante, y de igual forma como ocurrió en la antigua Grecia, solamente podía elegir un grupo selecto que excluía a mujeres, nativos, 
negros, pobres y esclavos. Con ello, se pasaba de la participación a la representación, y de la aristocracia hereditaria a una aristocracia elegida, pereciendo así el ideal de democracia ateniense del reparto igualitario de las oportunidades políticas, y surgiendo un sistema representativo que enfatizaba en la separación entre gobernantes competentes y gobernados incompetentes. En palabras del autor:

El sistema representativo tal vez fuera democrático por el derecho a voto, pero también era aristocrático debido al método de reclutamiento de candidatos: todo el mundo puede votar, pero la selección previa ya se ha realizado a favor de la élite (Van Reybrouck, 2017, p. 101).

Antes de culminar este capítulo, el autor menciona algunos acontecimientos que considera han sido importantes para consolidar la concepción de democracia como sistema representativo electoral republicano, destacando entre ellos la influencia de la obra de Tocqueville y la Constitución belga, que sirvió como esbozo de un modelo que tiempo después se convertiría en la norma internacional.

Finalmente, el capítulo Remedios constituye el apartado total de la obra, ya que aquí es donde el autor desarrolla las propuestas elaboradas tanto en el sector académico como en el político, para mejorar el desempeño de las democracias actuales. En concreto, van Reybrouck (2017) resalta primero el trabajo realizado por James Fishkin, quien plantea incorporar la autoselección, el sorteo y la deliberación durante los procesos de participación ciudadana. Asimismo, van Reybrouck (2017) menciona y describe de forma detallada varios de los procesos participativos que han surgido a principios de este siglo alrededor del mundo, destacando particularmente las reformas electorales realizadas en Columbia Británica (2004) y Ontario (20062007), Canadá; el intento de réplica de estas en los Países Bajos (2006); la Asamblea Constituyente de Islandia (2010-2012) derivada de la crisis financiera de 2008; y la reciente Convención Constitucional de Irlanda (2013). Dichas experiencias ejemplifican la pertinencia, relevancia y, sobre todo, la viabilidad de implementar la llamada democracia deliberativa.

En este cuarto capítulo, el autor también repasa algunas de las propuestas más interesantes para la repartición equitativa de las oportunidades políticas en la legislación. En ellas, sobresale la creación de asambleas elegidas por sorteo, una innovación legislativa que se plantea debe ir acompañada de procesos formativos y el apoyo de expertos hacia la ciudadanía. Cabe señalar que estas propuestas hacen referencia a la conformación de un órgano más representativo de la ciudadanía que no sustituye a la elección de miembros electos, sino que la complementa. De hecho, es precisamente esta idea la que lleva al autor a su propuesta central en la obra reseñada: la necesidad de crear un sistema birrepresentativo donde la representación popular sea obtenida tanto por elección como por sorteo, es decir, que el modelo electoral y el aleatorio vayan de la mano. $\mathrm{Al}$ actualizar los procedimientos democráticos con esta combinación, es posible atender las crisis de legitimidad y eficacia que amplian el abismo entre los ciudadanos y los gobernantes, y de paso, adaptar nuestras democracias a las necesidades del siglo XXI.

En suma, la obra de Van Reybrouck constituye una propuesta polémica, pero a todas luces válida, pues con argumentos sólidos y congruentes señala las limitaciones del modelo electoral, e invita indudablemente a la reflexión sobre el estado de las democracias occidentales contemporáneas. 